\title{
El lugar de la razón práctica en los discursos de aplicación de normas jurídicas *
}

\author{
JUAN CARLOS VELASCO ARROYO \\ Instituto de Filosofia del CSIC
}

Argumentar constituye un quehacer cotidiano para los diferentes operadores juridicos $\mathrm{y}$, de modo especial, para quienes desempeñan la función judicial. Dado que las decisiones de los jueces están sometidas a un cierto control de racionalidad, es posible concebir las argumentaciones jurídicas cmplcadas en la aplicación del derecho como un modo institucionalizado de ejercitar la racionalidad práctica. Sin embargo, esto no implica, en contra de lo que a menudo se suele afirmar, que los procesos argu- mentativos jurídicos estén sujetos en exclusiva a las leyes de la lógica deductiva. Cabe sostener el carácter racional de la aplicación del derecho sin caer en un logicismo a ultranza ni en una defensa de las artes de la retórica y de la tópica: ahí está, entre otras, la vía defendida por la teoría discursiva de la argumentación jurídica claborada por Robert Alexy a partir de presupuestos básicamente habermasianos, así como las correcciones contextualistas de la misma llevadas a cabo por Klaus Günther.

La práctica cotidiana del derecho se asienta básicamente en una serie de procedimientos discursivos que sirven de cauce a operaciones interpretativas y argumentativas. Argumentar es, en definitiva, el quehacer central de los juristas, de tal modo que de pocas actividades sociales se puede predicar un carácter más marcadamente argumentativo que de aquellas relacionadas con el derecho. Los desacuerdos que a menudo se producen entre los distintos operadores juridicos son desacuerdos interpretativos que se saldan mediante argumentos, es decir, por medio de proposiciones encadenadas de tal manera que de ellas se sigue una determinada conclusión. Al respecto resulta ilustrativa la doctrina adoptada por el Tribunal Constitucional alemán: «La interpretación del derecho constitucional tiene el carácter de un discurso en el que [...] hacicndo valer razones y contra-razones se llega finalmente a las mejores razones» [BVerfGE, 82, 30 (38-39), II, 1990]. Esta doctrina podria, en principio, extenderse al conjunto del derecho, esto es, a todas las prácticas argumentativas que tienen lugar en los distintos momentos de la actividad jurídica, entre los que cabe destacar tres ámbitos: la actividad legislativa productora del derecho positivo; la dogmática como ámbito privilegiado de reflexión teórica de los juristas pro-

* El título de este artículo constituye un modesto homenaje a Stephen E. Toulmin y a su libro An Examination of the Place of Reason in Ethics (Cambridge, 1950), que sin duda fue una obra pionera en aquella cmpresa filosóftica de las últimas décadas que se ha convenido en llamar la rehabilitación de la razón práctica. 
fesionales, y, por supuesto, la acción judicial en el marco codifícado de un proceso como lugar más representativo de la aplicación del derecho. Este artículo versarả esencialmente sobre la argumentación en este último ámbito.

Entre los diferentes operadores jurídicos, los jueces son ciertamente quienes han desarrollado unos hábitos argumentativos más depurados. Hábitos, en cualquier caso, mucho más persuasivos que las exposiciones de motivos de los textos legales, por no hablar ya de las tan a menudo infundadas motivaciones con que los órganos administrativos suelen contestar las demandas de los ciudadanos. Sólo la dogmática jurídica presenta un nivel argumentativo comparable. A ello contribuye la obligación que tiene el juez de explicar y justificar sus decisiones ', pues para êl, al contrario que para el legislador, no vale la máxima auctoritas, non veritas facit legem, sino la inversa veritas, non auctoritas facit iudicium (cfr. Ferrajoli, 1995, 35-37). En el mismo sentido se manifiesta el Tribunal Constitucional alemán, ya que al exigir que los magistrados basen sus decisiones «en argumentaciones racionales» [BVerfGE, 34, 269 (287), 1973] implícitamente está señalando la vinculación cxistente entre el carácter argumentativo de la praxis jurídica y la noción de racionalidad. Esta exigencia de racionalidad asignada a la argumentación judicial - coincidente con la expresada en la mayoría de los sistemas jurídicos occidentales como, por ejemplo, en la Constitución Española de 1978, en el sentido de que las sentencias sean siempre motivadas (art. 120.3) - no vendría dada tan sólo por el afán de mantener el estatuto cientifico de la jurisprudencia, sino sobre todo por la pretensión de legitimidad (o dicho en términos bastante más laxos, de aceptación social) que acompaña a las decisiones judiciales. Si esto último es así, el tema aquí tratado resultaría entonces relevante no sólo para los profesionales del derecho, sino también para todo ciudadano interesado por el buen funcionamiento de las cosas públicas (cfr. Alexy, 1989, 19).

Es preciso tener en cuenta que los modos propios de la argumentación jurídica han ejercido una enorme sugestión en la reflexión filosófica y a lo largo de la historia se han presentado a menudo como modelo o matriz del razonamiento práctico general. Pero las influcncias también se han dado en la dirección opuesta: así, la relevancia que actualmente se atribuye a la teoría de la argumentación está estrechamente relacionada con las diversas tentativas de rehabilitación del uso práctico de la razón, esto es, con los empeños por devolver a la razón la facultad de hablar sobre los asuntos prácticos relativos a la organización de la convivencia humana. Bajo capa de rigor intelectual, la filosofía positivista -imperante socialmente desde el siglo pasado- ha solido

'El término "decisión judicial» es ambiguo, pues hace referencia tanto al wacto de decidir" -con sus innegables implicaciones psicológicas de dificil objetivación- como al "contenido o resultado de ese acto de decidir», que puede y debe ser objeto de justificación racional. A lo largo de este artículo se utiliza el término en esta última acepción, de manera que se obviará el «contexto de descubrimiento» y las «razones explicativas» de la decisión. La atención se fijará, por el contrario, en el «contexto de justificación» y en las «razones justificativas» aducidas por el operador jurídico. 
concebir la pretensión de objetividad que guía el quehacer cicntífico como neutralidad valorativa. El efecto de esta actitud no ha sido otro que una preocupante abstinencia moral que amenaza con dejar a los individuos desarmados de argumentos con los que afrontar racionalmente los continuos retos prácticos de la vida. Frente a esta estrecha noción de racionalidad encarnada por el positivismo, las teorías de la argumentación suministran instrumentos conceptuales mucho más idóneos para resolver los numerosos problemas del quehacer humano. Prcsuponen, en definitiva, algo sumamente valioso: que existe la posibilidad de elección razonable basado en la deliberación intersubjetiva.

A lo largo de este artículo se tratará, en primer lugar, de exponer alguna de las razones que explican el auge de la teoría de la argumentación jurídica y su posición central en la actual teoría del derecho (I); a continuación se presentan los rasgos principales de la teoría desarrollada por Robert Alexy, que en cierta medida se ha convertido en la teoría «estándar» (II), y finalmente, se hará una revisión crítica de la misma, introduciendo especialmente algunas correcciones propuestas por Klaus Günther (III).

\section{Sobre la naturaleza de la argumentación jurídica}

El hecho de afirmar, como se ha hecho anteriormente, que la práctica jurídica presenta un fuerte carấcter argumentativo y que además está sujeta a condiciones de racionalidad no implica, sin embargo, sostener que los procesos argumentativos jurídicos están sometidos exclusivamente a las reglas de la lógica, al menos de la lógica deductiva moderna o lógica simbólica ${ }^{2}$. De la naturaleza no estrictamente lógica del razonamiento jurídico se ha sido consciente a lo largo de la historia del derecho occidental. Con todo, este convencimiento no ha impedido que en ciertos momentos se llegara a pensar que el proceso de decisión jurídica estaba determinado exclusivamente por los textos legales vigentes y que los jueces, en consecuencia, podrian resolver todos los litigios mediante la rígida aplicación de las reglas y principios del derecho. Esta creencia derivó con el tiempo en una concepción dogmática de la aplicación del derecho según la cual la decisión jurídica se sigue de modo necesario y aproblemático de las normas en vigor. A la formación de esta doctrina no le era ajeno el pensamiento cartesiano y su tendencia a identificar lo racional con la razón deductiva, con el more geométrico de pensar. Así, la labor judicial se reduciría presuntamente a realizar una determinada operación mental conocida como silogismo judicial (un caso de aplicación del modus barbara, aunque también podría formalizarse como un caso del cálculo de la lógica de predicados), que según suele describirse se limita a derivar una sentencia (la conclusión

"No obstante, hay quienes consideran que el razonamiento jurídico, en cuanto proceso argumentativo justificatorio de una decisión, es esencialmente un proceso deductivo: v. gr. Alchourrón y Bulygin, 1991. 
lógica) a partir de una norma o conjunto de normas (la premisa mayor), tras la subsunción de los hechos relevantes (la premisa menor) bajo el supuesto regulado por la ley ${ }^{3}$. Una dudosa inferencia normativa en realidad, pues al menos una de las premisas y la conclusión son normas y esta circunstancia resulta difícilmente asimilable por una lógica bivalente como es la lógica simbólica. Además, según esa misma concepción, el juez sería, empleando la famosa expresión de Montesquieu, la «boca muda» de la ley, de tal manera que no tendría que hacer otra cosa que establecer los hechos para que la consecuencia jurídica prevista en la norma se produjera de una manera automática ${ }^{4}$.

Si en la práctica se constata la imposibilidad de proceder de este modo ${ }^{5}$, en el orden teórico al abandono de la visión «logicista» del método jurídico contribuyó enormemente la filosofía del lenguaje contemporánea. A ella se debe la concepción del derecho como un conjunto de enunciados lingüísticos denominados «normas» y la distinción, hoy igualmente trivial, entre principios y reglas, como especies de ese género común ${ }^{6}$. Este enfoque filosófico va más allá y, entre otras cosas, ha puesto de manifiesto la indeterminación característica del lenguaje jurídico y la consiguiente discrecionalidad del íntérprete. Aunque un cierto afán de rigor no es ajeno al lenguaje del derecho, el uso de las normas jurídicas no está exento de una cicrta ambigüedad y de un grado de vaguedad o imprecisión que resulta imputable a la «textura abierta»

${ }^{3}$ La versión emblemática del denominado «silogismo judicial» se remonta a un pasaje que data de 1766: «En todo delito debe hacerse por el juez un silogismo perfecto. Pondráse como mayor la ley general, por menor la acción conforme o no a la ley, de que se inferirá por consecuencia la libertad o la pena. Cuando el juez, por fuerza o voluntad, quiere hacer más de un silogismo, se abre la puerta a la incertidumbre. No hay cosa tan peligrosa como aqucl axioma común que propone por necesario consultar el espíritu de la ley. Es un dique roto al torrente de las opiniones» (Beccaria, 1988, 31-32).

" ros jueces de la nación no son, como hemos dicho, más que la boca que pronuncia las palabras de la ley, seres inanimados que no pueden moderar ni la fuerza ni el rigor de la ley» (Montesquieu, 1993, lib. XI, cap. VI, 112). Desde una perspectiva histórica, el cometido que Montesquieu adjudica a la magistratura significa, sin duda, un paso positivo en la unificación y racionalización de la aplicación del derecho: el juez dejaba de ser creador del derecho-como to era hasta entonces en cuanto mediador e intérprete de las múltiples y variadas notmas existentes que configuraban el amasijo informe y contradictorio del sistema jurídico propio del Antiguo Régimen-y se convertía cn mero aplicador de reglas fijadas por la autoridad política y recopiladas de manera coherente, en tanto que funcionatio controlado por el gobierno y privado de poder discrecional.

${ }^{5}$ El esquema de aplicación del derecho, sbasado en la idea del juicio como silogismo perfecto y del juez como boca de la ley, tiene una intrínseca debilidad política debida, entre otras cosas, a que es totalmente inaceptable desde el punto de vista epistemológico y, por consiguiente, juridicamente impracticable» (Ferrajoli, 1995, 23).

'Los principios son, según la caracterización de Alexy, unormas que ordenan que se realice algo en la mayor medida posible, en relación con las posibilidades juridicas y fácticas. Los principios son, por consiguiente, mandatos de optimización que se caracterizan porque pueden ser cumplidos en diversos grados\%. Por su parte, las reglas son «normas que cxigen un cumplimiento pleno, y en esa medida pueden ser siempre sólo o cumplidas o incumplidas" (Alexy, 1989, 143-144). Sobre la configuración más o menos wabierta» o kcerrada» de las condiciones de aplicación de estos diferentes tipos de normas, cfr. Prieto Sanchís, 1992; Atienza y Ruiz Manero, 1996, 26-44. 
de todo lenguaje (cfr. Hart, 1963, 155-169). Mediante este tecnicismo se pretende expresar, haciendo uso de la terminología de Frege, el hecho de que la extensión o referencia de los términos no está prefijada de antemano por la intención o sentido de los mismos. Si además se tiene en cuenta «la incapacidad humana para anticipar el futuro» sobre el que se aplicarían las normas jurídicas (Hart, 1963, 163), parece inevitable que surjan importantes "zonas de penumbras sobre la posible extensión de los enunciados deónticos típicos del derecho. Este conocido fenómeno afecta en realidad a todo el lenguaje jurídico, pues como sostiene Peczenik $(1992,328)$, «no sólo los principios, sino también algunas reglas crean un deber meramente prima facie y, por consiguiente, exigen deliberación (esto es, sopesar y ponderar)». Aunque la «textura abierta» del lenguaje resulta ya considerable en el caso de las reglas, representa un obstáculo mayúsculo a la hora de especificar el contenido de los principios jurídicos - que como es sabido, a partir sobre todo de la obra de Ronald Dworkin Los derechos en serio, han sido rehabilitados como piezas elementales de la práctica jurídica-. Teniendo presente este hecho, la sola ayuda del instrumental lógico parece a todas luces insuficiente para realizar esa operación insoslayable $-\mathrm{y}$ previa a cualquier aplicación directa del derecho- que es la interpretación jurídica entendida como la labor de reducción de la incertidumbre semántica de las normas mediante la atribución de un determinado sentido.

El razonamiento jurídico no es un proceso cuasimecánico, sino algo bastante más sutil: en primer lugar, porque el derecho no es un sistema axiomático susceptible de someterse a un cálculo lógico exhaustivo; y, en segundo lugar, porque a la hora de aplicarlo hay que hacer necesariamente uso de complejas artes hermenéuticas tanto $\mathrm{cn}$ el contexto de justificación de las decisiones como, por supuesto, en el contexto de descubrimiento o selección de las premisas fácticas y normativas, esto es, en la determinación de las cuestiones de hecho y de derecho. $O$ dicho ahora con palabras de Habermas $(1998,585)$, las leyes y demás normas jurídicas «no tienen normalmente una forma semántica tal ni un grado de determinación tal que sólo deje al juez la posibilidad de una aplicación algorítmica. Como demuestra la hermenéutica filosófica, las operaciones interpretativas en la aplicación de las reglas comportan siempre operaciones constructivas que desarrollan el derecho".

Aunque sobre el carácter no estrictamente deductivo de la argumentación jurídica parece existir en nuestros días un consenso bastante generalizado, entre los cultivadores de la metodología jurídica ${ }^{7}$ hay quienes piensan, no obstante, que en los casos prácticos más usuales (los denominados «casos fáciles», pues

? Valga como botón de muestra la siguiente cita: «La decisión jurídica, que pone fín a una disputa juridica, expresable en un enunciado normativo singular, no se sigue lógicamente, en muchos casos, de las formulaciones de las normas que hay que presuponer como vigentes, juntamente con los enunciados empiricos que hay que reconocer como verdaderos y probados» (Alexy, $1989,23)$. 
en principio parecen contar con una solución predeterminada no discutida por la comunidad jurídica) el proceso argumentativo sí que se ajustaría a un sencillo esquema lógico. Pero, en realidad, como afirma Bayón (1996, 43, nota 14), «el conjunto de operaciones mentales que realiza el juez no se agota nunca en una mera inferencia deductiva. En particular, no tiene nada que ver con la lógica la operación de subsunción que lleva a establecer que el caso individual que juzga constituye un supuesto del caso genérico al que se refiere la norma que aplica [...], la lógica tiene que ver con las relaciones entre proposiciones [...], es decir, entre entidades lingüisticas, no con relaciones entre el lenguaje y el mundo». Si esto es así, constituiría sin duda un sano ejercicio de higiene mental evitar la confusión entre el estudio de la estructura del razonamiento y el difícil análisis del tránsito desde el razonamiento teórico hasta el momento de la acción o intervención en el mundo de los hechos.

Los primeros intentos destinados a afinar el análisis de las argumentaciones jurídicas se orientaron a mediados de este siglo hacia la lógica jurídica, entendiendo por tal bien una lógica específica de los juristas, bien una lógica propia del derecho como sistema normativo ${ }^{8}$. Entre los representantes más conspicuos de esta tradición que pretendía apurar las posibilidades de la lógica en el razonamiento jurídico se cuentan tanto Ulrich Klug (Juristische Logik, 1951) como Georges Kalinowski (Introduction a la lógique juridique, 1965). Klug (1961), en particular, recopila y analiza los argumentos especiales empleados en el derecho para elaborar una teoría de la lógica jurídica. Aunque en escríos posteriores Klug llega a admitir la irrelevancia de la lógica en determinados $\operatorname{casos}^{9}$, su obra constituye una de las tentativas más convincentes de aplicar los instrumentos de la lógica formal deductiva al análisis de las formas típicas del razonamiento jurídico. Esa lógica jurídica no ha sabido, sin embargo, dar una respuesta acertada a algunos de los problemas más acuciantes planteados al razonamiento jurídico: la carencia de información factual a la hora de decidir un caso (lagunas de conocimiento) y la ausencia o falta de previsión normativa aplicable al caso contemplado (lagunas o vacíos normativos). $\mathrm{Ni}$ tampoco ha sabido enfrentarse con la falta de coherencia de los ordenamientos legales positivos, en los que existe la posibilidad nada remota de que se generen conflictos o dilemas, como ocurre con las llamadas antinomias legales (disposiciones que proporcionan soluciones normativas contradictorias al mismo supuesto de hecho) ${ }^{10}$. Y por si esto fuera poco, en el ámbito jurídico abundan las cuestiones

* Aunque se ha intentado trazar una línea divisoria que separe los estudios sobre la «lógica de los juristas», entendida como investigaciones sobre el razonamiento de los juristas, de los estudios sobre la "lógica del derecho», en el sentido de investigaciones sobre la estructura lógica de las proposiciones jurídicas (cfr. Bobbio, 1965, 22-23), parece obvio que los límites entre ambas parcelas son bastante fluidos (cfr. García Amado, 1988, 188-191).

${ }^{9}$ Así, reconoce que sexisten contextos en los cuales, no obstante la relevancia de la respectiva argumentación para la decisión, es irrelevante que aquélla sea contradictoria o que de alguna otra manera viole las leyes de la lógicas (Klug, 1989, 83).

- Sobre las antinomias y las lagunas como escollos clásicos a las pretensiones de coherencia e integridad del ordenamiento jurídico, cfr. Bobbio, 1991, 116-219 y 221-252. 
que aparentemente permiten más de una salida y que requieren, sin embargo, llegar a una respuesta que se configure como solución práctica. Ante la imposibilidad de dar cuenta de todos estos fenómenos sólo mediante el instrumental técnico de la lógica simbólica, se ha producido una rebelión contra el formalismo juridico, contra la ilusión de certeza y aplicabilidad mecánica del derecho. Tal rebelión antiformalista, que reproduce muchos argumentos propios del realismo jurídico, ha conducido a numerosos estudiosos de estos temas a la elaboración de teorías que podrian denominarse paralógicas, las más de las veces completamente ad hoc, entre las que ocupan un lugar destacado la tópica jurídica de Theodor Viehweg y la nueva retórica de Chaïm Pcrelman.

La obra de Theodor Viehweg, Topik und Jurisprudenz (1953), debe entenderse como una seria tentativa de singularizar el tratamiento de los problemas de la argumentación como algo distinto del «espiritu deductivo sistemático", esto es, de lo estrictamente apodíctico; partiendo de los «argumentos ya dispuestos» (creados a partír de los topoi o loci communes), tales cuestiones se inscribirían más bien, en el terreno de la dialéctica, esto es, el arte de disputar o «técnica del pensamiento problemático» (cfr. Vielnweg, 1986, 24, 38 y 54). Por su parte, la nueva retónica de Perelman ha ejercido durante mucho tiempo de modelo alternativo que, frente a la tradición más formalista representada por Klug, trataba de dar cuenta del proceso de decisión allí donde la lógica y, en particular, los razonamientos analíticos o deductivos no resultan suficientes. La teoria de la argumentación pasaba a entenderse como una teoría general del discurso persuasivo, que como tal no podia descuidar las relaciones pragmáticas entre el orador y el auditorio ". Estas teorías alternativas adolecen, no obstante, de una debilidad común; pues una cosa es reconocer que el puesto de la lógica deductiva en el derecho es limitado y otra muy diferente es sostener que la lógica no juega ningún papel en la argumentación jurídica. Esta debilidad no es periférica ni lateral en dichas teorías, sino central, y por tanto debe ser solventada.

Con el objeto de encontrar una salida a esta dificultad y de dar cuenta de manera satisfactoria del carácter hermenéutico-argumentativo de la praxis jurídica, numerosos teóricos del derecho se han dedicado en los últimos años a construir modelos destinados a detallar los procesos discursivos que tienen lugar en la práctica real del variopinto mundo del derecho (las denominadas teorías empíricas o descriptivas), así como a analizar la estructura de los argumentos jurídicos (las llamadas teorías analíticas) o bien a establecer los patrones o cánones de la argumentación racional, tanto en lo relativo a su corrección formal como en lo relativo a su rectitud material o racionalidad de sus premisas

"El empeño de Perelman por otorgar a la (nueva) retórica un lugar en la práctica argumentativa le lleva a oponerse a aquellos que consideran que «desde el momento en que hay controversia y los métodos "lógiconexperimentales" no pueden restablecer el acuerdo de los espíritus, se está en el campo de lo imacional, que sería el de la deliberación, la discusión, la argumentación” (Perelman, 1989, 770). 
(teorias prescriptivas o normativas) ${ }^{12}$. Entre las diversas propuestas teóricas destacan dos que, en principio, pretenden ser simultáneamente descriptivas, analíticas y normativas: las teorias de Neil MacCormick y Robert Alexy. Aunque elaboradas en el seno de dos culturas jurídicas bien diferentes como son la tradición anglosajona del common law y la dogmática jurídica germánica, sostienen tesis muy semejantes entre sí: ambas teorías defienden que el argumentar jurídico no es una actividad que se diferencie radicalmente del argumentar moral o del práctico en general, sino tan sólo por su mayor grado de institucionalización y formalización. En poco ticmpo han logrado convertirse, como afirma Atienza $(1992,11)$, en el modelo «estándar» de la argumentación jurídica. Debido, en primer lugar, a su inserción en la práctica judicial más propia del continente europeo y, en segundo lugar, a su mayor grado de formalización, paso a continuación a exponer en sus rasgos generales la teoría de Robert Alexy.

\section{La teoría del discurso práctico como modelo de la argumentación juridica}

El libro básico de Alexy a este respecto, Teoria de la argumentación jurídica, ha de encuadrarse entre los diversos intentos de construir modelos de racionalidad que sirvan de guía para la toma de decisiones prácticas en la esfera jurídica. Desde su publicación en 1978, Alexy ha ido desarrollando y precisando su teoría en numerosos artículos, pero sin modificarla en lo fundamental. Con respecto a otras teorías de la argumentación jurídica, el depurado modelo construido por Alexy tiene la particularidad de partir no de las argumentaciones reales tal y como tienen lugar en las diversas instancias jurídicas (especialmente en los órganos aplicadores del derecho), sino de una teoría general de la argumentación práctica para luego descender al mundo jurídico. En su búsqueda de un paradigma para la teoría de la argumentación jurídica, Alexy no encuentra uno más apropiado que la teoría general del discurso práctico racional elaborada por Habermas. Asi, y aunque Alexy construye su teoría sobre la base de una discusión con diversas teorías analíticas (entre otros, Wittgenstein, Austin, Stevenson, Hare o Toulmin), así como con la nueva retórica de Perelman, la teoria discursiva constituye su principal referente hasta tal punto que, como afirma Atienza $(1981,178)$, «la teoría de Alexy viene a significar, por un lado, una sistematización y reinterpretación de la teoría del discurso práctico habermasiana y, por otro lado, una extensión de esta tesis al campo específico del derecho». Habria que precisar, no obstante, que ésta no es la única aplicación posible del modelo habermasiano al mundo jurídico.

${ }^{12}$ Una completa visión de conjunto sobre esta serie de teorias puede encontrarse en Atienza, 1991. Ahi se ofrece un pormenorizado análisis de la tópica de Theodor Viehwcg, la nucva retórica de Chaïm Perelman, la lógica informal de Stephen Toulmin y las concepciones de Neil MacCormick y de Robert Alexy, además de un avance de la teoría del propio autor. 
El actual auge de la teoría de la argumentación jurídica no puede entenderse cabalmente sin la reformulación del concepto de «razón práctica» en términos de «razón comunicativa»; una ambiciosa tarea intelectual en la que, sin lugar a dudas, la contribución de Habcrmas resulta fundamental. La tcoría habermasiana de la racionalidad comunicativa se centra, como es sabido, en el análisis de las condiciones y estructuras básicas de la argumentación, esto es, en ofrecer una versión discursiva de la accptabilidad racional de nuestras teorías y enunciados. Este empeño básico resulta coherente tanto con su concepción de la verdad como «aceptabilidad racional en condiciones ideales» como con la intuición compartida por numerosos cultivadores de la ética y de la filosofía del derecho de que la argumentación, en forma de discursos prácticos, ocupa un lugar central en nuestras prácticas de evaluación de la rectitud o corrección de los enunciados normativos, en especial de los jurídicos.

Antes de proseguir sería conveniente aclarar la noción de «discurso», sobre la que se volverá de modo repetido a lo largo de este artículo. La idea, en principio, parece sencilla: un discurso, en el sentido técnico aquí seguido, es un acto lingüistico entre varios participantes con opiniones contrapuestas que, con el fin de llegar a resultados válidos, se atienen a determinadas reglas ${ }^{13}$. En esta peculiar actividad lingüística se convierten en tema explícito las pretensiones de validez que se han tornado problemáticas a lo largo de la comunicación, de tal modo que la investigación de su posible justificación constituye el objetivo perseguido en común (cfr. Habermas, 1987, 43-69). De hecho, la mera formulación de una pretensión de validez es una invitación implícita a iniciar un debate. Cuando las pretensiones de validez cuestionadas no pueden ser dilucidadas de modo argumentativo las únicas salidas que quedan son o bien un comportamiento de carácter estratégico ${ }^{14}$ o bien la ruptura de la comunicación. Y en la práctíca, el abandono de la actitud comunicativa abre el paso a la confrontación abierta. Por el contrario, el discurso argumentativo, como el encarnado en los procedimientos jurídicos, representa una vía cooperativa y pacífica de resolución de los conflictos, ya que «la única presión permitida en el discurso es la del mejor argumento, y el único motivo admitido, el de la búsqueda cooperativa de la verdad» (Habermas, 1982, 313).

${ }^{13}$ El término alemán «Diskurs» ha sido traducido habitualmente por «discurso», una opción que se mantendrá aquí aunque en castellano el sentido de esta palabra resulte próximo al de «monologon, sea êste interior o público, escrito o hablado. En realidad, la palabra alemana se acerca más a lo que en castellano conocemos por «debate», que tal como sostiene el DRAE implica una «controversia sobre una cosa entre dos o más personas».

${ }^{14}$ En las denominadas acciones estratégicas no se busca tanto el acuerdo común cono el éxito individual. Un caso ejemplar de actuar estratégico es la negociación de compromisos (y no, en cambio, aunque pueda parecer lo contrario, la vista de una causa civil o penal, en donde si existe un afän de rectitud normativa): «La negociación de compromisos no se halla al servicio de un desempeño estrictamente discursivo de pretensiones de validez, sino del ajuste de intereses no susceptibles de universalización, y ello sobre la base de un cquilibrio de posiciones poder" (Habermas, 1987, vol. 1, 60). De todas formas, hay una serie de fenómenos que no pueden ser fấcilmente clasificados como discurso o como acción estratégica (cfr. Alexy, 1989, 212). 
Cuando en medio de una interacción comunicativa uno de los hablantes sostiene un determinado enunciado está dando a entender la posesión de razones suficientes para que dicho enunciado sea aceptado por los demás interlocutores, de tal suerte que si esta pretensión es puesta en duda por alguno de ellos puede pasar a justificarla de modo explícito. Esto vale tanto para el discurso teórico como para el práctico. La diferencia entre uno y otro tipo de discurso estriba en que la pretensión de validez problematizada en el discurso teórico es la de verdad, y su justificación se realiza aduciendo hechos como razones, mientras que en el discurso práctico la pretensión de validez es la rectitud o corrección normativa, y su defensa se lleva a cabo mediante la invocación de normas socialmente compartidas ${ }^{15}$.

Un «discurso práctico» surge, pues, cuando se pone en cuestión la pretensión de rectitud normativa de los actos de habla regulativos o prescriptivos (entre los que se encuentran las órdenes, las promesas, las propuestas o recomendaciones prácticas y también la reivindicación de los derechos). Al plantear una pretensión de rectitud normativa el hablante se obliga a justificar que su juicio práctico es normativamente correcto. Lo que se convierte en objeto de examen discursivo no es la pretensión de rectitud directamente ligada al acto de habla, sino la pretensión de validez de la norma subyacente (cfr. Habermas, $1989,363-364$ ). Cualquier acto de habla puede ser criticado como no válido en el sentido de no correcto en relación a los contextos normativos vigentes (en esto estribaría, en principio, el sentido de la pregunta jurídica por la legalidad de una norma) o criticando, más radicalmente, la propia legitimidad de la norma que presupone.

El punto decisivo en los discursos prácticos no es tanto que en ellos se pongan en cuestión normas o reglas, sino que los se lleven a cabo siguiendo determinadas reglas. Los discursos constituyen un tipo de juego de lenguaje. Tal como advirtió Wittgenstein (1988), cualquier juego (v. gr. el ajedrez, el mus o el fútbol) es una actividad intersubjetiva guiada por reglas. Esto no implica que en el juego todo esté previamente determinado, y menos aún en el juego argumentativo: las reglas del discurso práctico «no determinan, de ninguna manera, el resultado de la argumentación en todos los casos, sino que excluyen de la clase de los enunciados normativos posibles algunos (como discursivamente imposibles), y por ello imponen los opuestos a estos (como discursivamente necesarios)» (Alexy, 1989, 36-37). De este modo, Alexy persigue situarse en un punto intermedio entre el determinismo y el decisionismo, entrc el dogmatismo y el total relativismo. No trata de condicionar de entrada el pluralismo valorativo de las sociedades contemporáneas, pues así su teoría procedimental quedaria invalidada por puro desconocimiento de la realidad

${ }^{15}$ El saber implicado en uno y otro discurso es distinto: en nuestras afirmaciones de enunciados verdaderos el saber depende de la existencia de determinados estados de cosas en el mundo objetivo; en nuestra defensa de normas el saber depende de la existencia de intereses generalizables compartidos por todos los individuos en el mundo social (cfr. Habermas, 1991, 130). 
epocal. Precisamente por tener presente esta dificultad dicha teoría no se interesa tanto por cuál sea el resultado al que se llegue como por el hecho de que se siga el procedimiento adecuado, ya que presupone que la corrección del proceso se transfiere siempre al resultado (como sucede, v. gr., en el clásico caso de una división en porciones iguales, en donde quien corta el pastel debe tomar el último pedazo). La formulación de un conjunto de reglas elementales de juego tiene para la teoría del discurso el marcado propósito de lograr un procedimiento capaz de diferenciar las justificaciones válidas de las proposiciones normativas de aquellas otras justificaciones consideradas normativamente inaceptables.

Los principales elementos de la teoria de Alexy surgen de trasladar o adaptar las normas del discurso práctico general al ámbito particular de lo jurídico. Esto se compadece bien con la tesis de partida de esta teoría, esto es, con la idea de que la argumentación jurídica representa un caso especial del discurso práctico general $\mathrm{o}$, dicho de un modo más preciso, una modalidad institucionalizada de la argumentación moral. La argumentación jurídica es un tipo de discurso práctico porque en ella se discuten cuestiones que se refieren a la praxis humana y porque se plantea la pretensión de rectitud normativa. Representa un caso especial porque la argumentación se desarrolla en unas determinadas condiciones propias del marco jurídico que restringen el alcance de la rectitud normativa: ha de vincularse a la ley, a los precedentes judiciales y a la dogmática claborada por la cicncia jurídica (cfr. Alcxy, 1989, 205-213). Y es más, cl cjercicio de la argumentación jurídica está limitado en la práctica por la presión derivada de la escasez de tiempo disponible para llegar a una decisión y por las condiciones de conocimiento incompleto.

Según las tcorías procesales, la admisibilidad racional de una decisión depende del seguimiento de ciertas reglas. Si esto es así, el problema estribaría entonces en cómo derivar y fundamentar esas reglas que articulan el procedimiento. $Y$ lo cierto es que Alexy sólo ha formulado un conjunto de reglas, pero de ningún modo las ha fundamentado de modo concluyente. Se limita a indicar que para que el procedimiento discursivo $P$ resulte operativo se deberían tener en cuenta algunos requisitos referentes a los participantes en la argumentación y a las condiciones en que ésta debe llevarse a cabo, así como a la forma de los argumentos esgrimidos. Algunos de los requisitos de la argumentación recogidos por Alexy alcanzan, según él, el rango de reglas de carácter cuasi-trascendental, pues no se trata de meras convenciones, más o menos contingentes, sino de presupuestos inexcusables, de tal manera que sin ellos no sería factible dicha forma de comunicación (cfr. Alexy, 1989, 102).

Las reglas que, según Alexy, articulan el discurso práctico racional conforman, en realidad, un conjunto bastante abigarrado. Existen reglas que únicamente valen en el discurso práctico y reglas que son extensibles a otros juegos de lenguaje. Hay órdenes, prohibiciones y permisiones. Algunas reglas reclaman estricto cumplimiento, otras encierran exigencias que solamente pue- 
den ser satisfechas aproximadamente. Entre las distintas reglas hay unas que se refieren a la esfera lógica de los productos. Tales reglas consideran a la argumentación desde la perspectiva de la «producción de argumentos» pertinentes que convenzan en virtud de sus propiedades intrínsecas. Coinciden básicamente con las reglas de la lógica mínima, indispensables para la comprensión semántica de los contenidos enunciados, pues también las leyes de la lógica rigen en el discurso práctico. Otras reglas versan sobre la esfera dialéctica de los procedimientos. No se refieren al aspecto sintáctico, ni al semántico, sino a los supuestos pragmáticos que han de observar los participantes en el discurso. Un tercer tipo de reglas se ocupa del círculo retórico de los procesos. Se incluyen aquît tambiến reglas pragmáticas que tienen como principal función excluir las posibilidades de distorsión comunicativa. Aspiran a inmunizar los procesos argumentativos de los efectos de la represión política y de la desigualdad social. Articulan el reconocimiento de exigencias tan básicas como la igualdad de derechos de todos los participantes y la ausencia de coacción. Son reglas que garantizan la igualdad de los participantes en una acción orientada hacia el entendimiento, y revelan las estructuras de una situación discursiva no amenazada por la represión y la discriminación - sólo estaría permitida, en definitiva, la coacción llevada a cabo por la fuerza del mejor argumento.

El discurso argumentativo sometido a las reglas antes señaladas - una forma de comunicación, a decir verdad, relativamente infrecuente- apunta tendencialmente en su organización interna a la satisfacción de determinadas condiciones ideales. Como se han indicado anteriormente, la caracterización que Alexy hace del discurso práctico responde, en gran medida, a la intuición habermasiana de que la verdad y, mutatis mutandis, la corrección normativa deben entenderse como «aceptabilidad racional en condiciones ideales». De ahí que la teoría de Alexy pueda concebirse como una formalización de las suposiciones pragmáticas que, según Habermas, conforman la situación ideal de habla ${ }^{16}$. Este constructo contrafáctico se caracteriza por una distribución simétrica de las oportunidades y derechos de participación, es decir, por la ausencia de cualquier tipo de obstáculos, externos o internos, que puedan impedir la comunicación: «las exigencias de simetría y libertad planteadas por Habermas", sostiene Atienza $(1991,182)$, «constituyen el contenido de las reglas del discurso racional que Alexy denomina reglas de razón». La relación de simetría entre todos los participantes en el discurso (aquello que los áticos denominaban isegoría o «igualdad en el ágora») es una condición de posibilidad no ya trascendental, sino pragmática, del marco institucionalizado de la comunicación. No hay una auténtica comunicación si, de manera generalizada y recíproca,

${ }^{10}$ "Llamo ideal a una situación de habla en que las comunicaciones no sólo no vienen impedidas por influjos externos contingentes, sino tampoco por las coacciones que se siguen de la propia estructura de la comunicación. La situación ideal de habla excluye las distorsiones sistemáticas de la comunicación. Y la estructura de la comunicaciôn deja de generar coacciones sólo si para todo participante en el discurso está dada una distribución simétrica de las oportunidades de elegir y ejecutar actos de hablas (Habermas, 1989, 153). 
no se reconocen a todos los mismos derechos. Ninguna norma puede ser reconocida como válida si no es el resultado de una deliberación colectiva en la que la participación en igualdad de oportunidades de todas las personas se encuentre suficientemente garantizada. En definitiva, Alexy comparte básicamente los planteamientos de una «teoria discursiva del derecho» que, como sostiene Habermas $(1998,297)$, whace depender la aceptabilidad racional de las sentencias judiciales no sólo de la calidad de los argumentos, sino también de la estructura del proceso de argumentación'. En descargo de Alexy debe apuntarse que esta propensión idealizante es compartida por otras teorías de la argumentación jurídica: recuérdese la noción del «espectador imparcial» de MacCormick, la de «auditorio universal» de Perelman o la apelación de Dworkin a un «juez Hércules». De modo semejante, la construcción de Alexy propugna también un ideal regulativo de corrección destinado a evaluar las pretensiones de validez del discurso jurídico en tanto que un subapartado del discurso práctico general.

El sistema normativo implícito en la lógica de la argumentación podría concebirse como un código de mínimos. En la práctica, este código coincidiría básicamente con la moral postconvencional de principios, pues incorpora unos derechos básicos que delimitan un ámbito de actuación del individuo reconocido y protegido intersubjetivamente ${ }^{17}$. Los preceptos normativos de la comunicación pretenden tener un alcance universal, pues exige una igual consideración de todos los individuos.

\section{El discurso juridico como discurso de «aplicación de normas}

Tras presentar hasta aquí los trazos generales de la teoría de la argumentación jurídica de Alexy, así como sus principales consecuencias normativas, es ahora el momento de realizar un balance crítico. En su haber debe ponerse ciertamente el indudable mérito de haber explicitado la existencia de un estrecho nexo entre la argumentación jurídica y el discurso práctico general. Esto no impide, sin embargo, que pueda dirigirse contra la misma algunas objeciones que afectan a su núcleo central. En primer lugar, no es cierto que sea, como pretende, una teoría al mismo tiempo empirico-descriptiva, analítica y prescriptivo-normativa, pues en realidad es primordialmente prescriptiva a la hora de exponer

${ }^{17}$ "Se puede suponer que no sólo todos los princjpios morales pueden ser considerados como reglas de la argumentación moral, sino también que numerosas reglas del discurso moral pueden ser considerados como principios moralcs» (Alcxy, 1989, 100). En todo caso se trata de normas no creadas ex nihilo, sino extraidas del bagaje sociocultural disponible: «Las presuposiciones pragmáticas de la argumentación que analiza Alexy (así, la idea de la simetría de los participantes) y de las que parte Habernas para la justificación de la regla de universalidad (y, consiguientemente, del postulado discursivo D) están transidas de una normatividad que se supone y preinterpreta a la luz de asunciones normativas materiales concretas esa regla de universalidad» (Thiebaut, 1992, 195). 
las reglas y formas del discurso práctico general y resulta descriptiva a la hora de exponer las reglas y formas del discurso jurídico. Y en segundo lugar, tampoco parece del todo acertada la tesis, tan enfáticamente sostenida por Alexy, de que la argumentación jurídica - en el sentido en que él la concibe- sea un caso especial del discurso práctico en general, sino tan sólo, como ha mostrado Klaus Günther ${ }^{18}$, un caso especial del discurso práctico de fundamentación.

Las reglas consignadas por Alexy pueden concebirse, de hecho, como un despliegue pormenorizado del principio de universalización, que cs el principio que regula los procesos discursivos de fundamentación y justificación. Sin embargo, este principio, como señala Günther, no agota el sentido normativo de la imparcialidad que subyace a la noción de juicio justo y que el derecho como tal pretende encarnar. Además, tesulta estéril a la hora de indicar qué se debe hacer en una situación concreta. Los discursos de aplicación exigen una dinámica argumentativa diferente, pues si bien en el contexto de un «discurso de fundamentación» el problema se centra en la corrección de las nomas jurídicas ( $o$, en otras palabras, en su validez en abstracto), en los "discursos de aplicación» el tema se ciñe a la aclaración y justificación de la corrección de una decisión jurídica.

Alexy responde a la objeción de Günther aduciendo que aunque sea legítimo diferenciar entre la fundamentación y la aplicación de normas, en la práctica no es tan claro que la distinción entre ambos tipos de discursos resulte esencial. Más bien resulta irrelevante, porque, en su opinión, todo discurso de aplicación encierra en sí ya un discurso de fundamentación (cfr. Alexy, 1995, 52-70). Pero aquí sería oportuno recordar que la teoría de la argumentación jurídica desarrollada por Alexy es, como reza el subtítulo de su obra básica sobre el tema, una teoria del discurso racional entendida como teoría de la fundamentación jurídica y que, por tanto, no está concebida, por lo menos en principio, para dar respuesta a los problemas específicos que plantea la aplicación de normas. Ahí se encuentra, sin duda, su fortaleza, pero también su propia debilidad.

En el argumento de réplica que Alexy esgrime contra Günther -que los discursos de aplicación se encuentran ya contenidos en el discurso de fundamentación- subyace una velada remisión al ideal de "norma perfecta», pues con ella acaecería ciertamente la integración de ambos discursos. Ésta sería una norma tal que epodría regular su propia aplicación, porque todas sus posibles aplicaciones individuales habrían sido tema del discurso y la adecuación de su aplicación pertenecería al significado de su validez» (Günther, 1995, 279). Sin embargo, tal como advierte Günther (ibidem, 284), «el ideal de una norma perfecta subsume por error el concepto de adecuación en aquel otro de validez». Al poner de manifiesto lo incorrecto de este presupuesto implícito, Günther no hace sino recuperar oportunamente la idea aristotélica

is Véase la obra fundamental de este autor alemán: Günther, 1988. Para una presentación de la misma, cfr. Velasco, 1997. 
—que habitualmente también hace valer la hermenéutica jurídica- de que ninguna regla puede regular su propia aplicación o, dicho en relación al ámbito que nos ocupa, que las normas jurídicas no son ni autointerpretables ni autoaplicables. A esta importante razón de principio cabe añadir otra, quizás de menor alcance, relativa a la praxis cotidiana del derecho: «en los casos de colisión más interesantes no se trata de la validez, sino de la adecuación de una norma aplicable prima facie» (ibidem). Cabe entonces deducir que los dos problemas no sólo son conceptualmente diferenciables, sino también empíricamente, y que, en consecuencia, omitir dicha distinción constituye una seria falta de finura analítica.

El problema de la aplicación de las normas no estriba tan sólo en identificar qué normas superan un criterio de validez universal, sino en encontrar en cada caso particular, tras la completa descripción de sus circunstancias relevantes, la norma o normas que resultan aplicables. $Y$ la aplicabilidad de la norma no puede estar determinada de antemano, sino tan sólo su validez prima facie. La corrección normativa de una decisión es más bien relativa a la ocasión, a la circunstancia concreta; éste es el sentido del principio de la adecuación propuesto por Günther como guía en los procesos de aplicación de las normas, que es donde hay que desplegar toda la fuerza argumentativa de las razones disponibles. Este principio guarda a su vez una cierta afinidad con el sentido aristotélico de la prudencia y está abierto, por tanto, a la interpretación contextual de las circunstancias relevantes de cada caso.

La propuesta central de Günther podría resumirse en los siguientes términos: «Un enunciado normativo singular sólo puede pretender ser correcto si se apoya en una norma válida y en su adecuada aplicación» (Günther, 1995, 302). En consecuencia, un juicio práctico particular puede ser considerado correcto sólo si se apoya en normas válidas, ya sean reglas o principios, y si además se aplican adecuadamente a la situación concreta (ibidem, 227). En definitiva, cuando tratamos de la aplicación de normas no podemos hablar de normas válidas con independencia de la comprensión de las situaciones concretas. En los numerosos supuestos en los que la justificación lógico-deductiva de la decisión es insuficiente el intérprete ha de acudir a otros requisitos, tales como el criterio de «universalidad», así como a los principios de «consistencia» y dc «coherencia», que precisan el sentido de las premisas normativas en relación con el conjunto del sistema jurídico (cfr. Günther, 1995).

Como es sabido, una típica objeción del realismo jurídico -entre cuyos cultivadores cabe incluir también a los representantes de los Critical Legal Studies - consiste en afirmar que los sistemas jurídicos vigentes comprenden tantas normas contrapuestas -las conocidas antinomias normativas-, y el lenguaje jurídico posee tal grado de ambigüedad que resulta imposible adoptar una decisión de manera consistente. Pues bien, entre los méritos de la teoría de Günther se encuentra la aportación de una perspectiva teórica capaz de solventar o, al menos, aliviar precisamente esta objeción: la distinción siste- 
mática entre discursos de fundamentación y de aplicación permite separar con fundamento el caso de aquellas normas que mutuamente se contradicen del caso de aquellas normas que sólo entran en colisión en circunstancias singulares. Al diferenciar entre validez y adecuación de las normas se mitiga en cierta medida las contradicciones, aunque no hasta el punto de disolver la complejidad propia de los sistemas jurídicos contemporáneos. Al respecto, Günther (1995) hace suya una tesis fuerte como es el concepto normativo de coherencia en la aplicación judicial del derecho, cuyo alcance teórico resulta similar al de la concepción del «derecho como integridad» postulada por Dworkin (1988).

Alexy $(1989,274-277)$ mantiene la tesis de que las reglas y formas del discurso práctico general coinciden no sólo parcial, sino estructuralmente con las reglas y formas de la argumentación jurídica. Esto no parece, sin embargo, fácil de conciliar con la pretensión de validez débil que subyace al discurso jurídico, pues como afirma el propio Alexy: «con las afirmaciones y decisiones jurídicas no se pretende que éstas sean sin más correctas, sino sólo que sean correctas bajo el presupuesto del orden jurídico vigente; ello ocurre, sin que se puedan fundamentar racionalmente, teniendo en cuenta la ley, el precedente y la dogmática» (Alexy, 1989, 314). En virtud de este rasgo del discurso jurídico Günther $(1995,296-300)$ niega la coincidencia entre ambos tipos de discurso al advertir que una «fundamentación racional en el marco del ordenamiento jurídico vigente», como repetidamente señala Alexy (1989, 208, 213 y 274), no puede ser por definición una fundamentación de validez, tal como prescribe el discurso práctico general, porque forzosamente se ha de dar por sentado la validez de las normas o del ordenamiento jurídico en su totalidad. Dado que en tales discursos se presupone «ex definitione la validez de las normas" que se han de aplicar, la argumentación de los operadores jurídicos debe concebirse como un «caso especial del discurso moral de aplicación» (Günther, 1995, 300).

En Facticidad y validez, obra aparecida en 1992, esto es, con posterioridad a la publicación de los principales estudios tanto de Alexy como de Günther acerca de la teoría de la argumentación práctica, Habermas toma distancia con respecto a las respectivas posiciones de sus dos seguidores en esta materia: «La tesis que considera el discurso jurídico como caso especial del discurso moral, defendida en una u otra versión, resulta plausible desde puntos de vistas heurísticos, pero sugiere una subordinación errónea dcl derecho a la moral, no liberada del todo aún de las connotaciones del Derecho natural» (Habermas, 1998, 305). En ningún caso cabría deducir de la primacía heurística de los discursos práctico-morales que los discursos jurídicos representen en sentido estricto un mero subconjunto de los mismos, pues la mayor complejidad de la dimensión de validez de las normas jurídicas, así como «las restricciones específicas a que se halla sujeta la acción forense de las partes ante un tribunal, no parecen permitir que el curso del proceso pueda medirse por los criterios de un discurso racional» (Habermas, 1998, 303). 
Con respecto a la pretensión de universalidad de la teoría de la argumentación jurídica elaborada por Alexy -aunque, por supuesto, no sólo contra esta teoría- puede objetarse el marcado carácter particularista que rezuma su presentación. Si bien pretende ser un código mínimo con validez universal, en realidad constituye una forma particular de moralidad, la occidental, disfrazada bajo capa de neutralidad: «la moralidad mínima prescrita por estas teorías es simplemente una forma abstraída, y no muy lejana, de la cultura democrática contemporánca» (Walzer, 1996, 45). El procedimentalismo del que hace gala Alexy ciertamente pretende surtir de reglas generativas mínimas capaces de producir distintas formas normativas más detalladas, concretas y válidas localmente. Sin embargo, como afirma Walzer (1996, 44-45), «el mínimo procedimental resulta más que mínimo [...] La moralidad tenue ya es bastante densa». No resulta evidente, sin embargo, que el procedimiento general y abstracto de la teoría de la argumentación jurídica sea compatible con formas sociales y culturales diversas. Las reglas del juego argumentativo constituyen en la práctica una forma de vida no universalizable.

En la teoría de Alexy hay elementos que desmienten tanto el carácter neutral de las normas del procedimiento discursivo como su propia pretensión de universalidad. Sus reglas y formas de la argumentación jurídica no sólo coinciden con los principios de una moral postconvencional, sino básicamente con las reglas del Estado democrático de Derecho, pero idealizándolas, por lo que cabe decir que «su teoría de la argumentación cumple, entre otras, una función ideológica consistente en justificar - de manera acrítica- un determinado modelo de derecho» (Atienza, 1991, 231). En realidad, tanto la teoría discursiva del derecho elaborada por Habermas como la concepción de la justicia propuesta por John Rawls y, de manera aún más obvia, la teoría de la argumentación jurídica de Robert Alexy, proceden a partir de una forma concreta de vida en común que no es otra que la derivada de sus propias percepciones del funcionamiento del sistema democrático, esto es, un sistema caracterizado por la garantía de los derechos, la división de poderes y el control judicial de la legalidad. A partir de estas piczas normativas tan densas en contenido cultural estos autores hacen una especie de destilado del que se obtienen unas reglas en forma de procedimientos. Pero si de lo que se trataba era de fundamentar o justificar nuestras prácticas políticas y jurídicas, no parece muy lógico, sino más bien una trampa argumentativa, afirmar su bondad, porque se atienen a unas reglas que hemos obtenido a partir de esas mismas prácticas sociales. Lo máximo que cabe decir entonces de una práctica concreta es que se adccua o no a sus principios justificadores válidos en un determinado sistema normativo. Es decir, la teoría de la argumentación jurídica como teoría procedimental no tiene más valor, ni menos, que el que se desprende de su función de crítica interna de los sistemas juridicos y judiciales ya dados. De hecho, la justificación de cualquier decisión judicial no puede ser identificada como una fundamentación última del propio fallo. Busca tan sólo adecuar la sentencia 
a un horizonte normativo dado, que explícita o implícitamente ya ha sido aceptado socialmente. La argumentación judicial posee siempre un carácter penúltimo, al estar sujeta a las disposiciones emanadas de la voluntad del legislador, quc constituye el criterio supremo y último en el sistema. Su justificación sc establece en el marco de un ordenamiento jurídico, que en su totalidad apenas suele ser impugnado, excepto, claro está, en momentos revolucionarios. Por ello, una decisión jurídica argumentada —en el sentido de aceptable intersubjetivamente-- quiere decir, en el mejor de los casos, que dicha decisión se amolda al sentido de la justicia propio de un determinado sistema jurídico $y$, por ende, de una determinada comunidad política. Con esta puntualización se rebaja sensiblemente la pretensión de universalidad y objetividad de las teorfas procedimentales y se pone de manifiesto su dependencia tanto de determinadas constelaciones históricas contingentes como de ciertas comunidades locales ${ }^{19}$.

No cabe duda de que en el interior de estos marcos normativos de validez no universal, sino localmente delimitada, una teoría del discurso jurídico como la avanzada por Alexy o por MacCormick también puede aportar elementos valiosos. En especial, la introducción de exigentes requisitos de racionalidad en el procedimiento judicial contribuiría significativamente a sla paulatina reducción de la inseguridad en el resultado» (Utrera García, 1995, 377) de las decisiones judiciales que afectan al actuar concreto de los ciudadanos. La garantía de la seguridad jurídica - entendida como predecibilidad de los efectos jurídicos de los actos- pone remedio a esa necesidad tan humana de «saber a qué atenerse» para poder dar una estructura y un sentido a los planes particulares de acción. Esta prestación es sumamente relevante en un sistema socioeconómico que, como en el imperante mayoritariamente en el mundo contemporáneo, depende de las decisiones descentralizadas de actores autónomos.

Las reglas de la argumentación jurídica no eliminan el margen de maniobra de los jueces y demás operadores jurídicos dedicados a la aplicación del derecho, рето sí contribuyen a reducir drásticamente los espacios de discrecionalidad o de libre disposición. La obligación de razonar las decisiones en términos del derecho vigente, vinculando el juicio particular al sentido de justicia de un ordenamiento jurídico, pone las cosas en su lugar: un lugar intermedio entre dos extremos igualmente rechazables (cfr. Bayón, 1996). Por un lado, el activismo judicial, el denominado «gobierno de los jueces», que en última instancia conlleva que éstos se erijan en legisladores, choca frontalmente con

"Esta precisión sobre los límites de la argumentación jurídjca guarda una estrecha relación con la idea habermasiana de que es consustancial con la gramática de la palabra xfundamentar» (o, análogamente, «justificar» o kargumentar») una suerte de falibilismo entrecruzado con un cierto contextualismo: sel hecho de que mantengamos en el contexto en el que aquí y ahora nos situamos un determinado tipo de razones como las mejores no excluye a prioni la posibilidad de que en otros contextos podamos mantener como mejores otro tipo de razones) (Habermas, 1988,351 ). 
la idea del Estado de derecho, es decir, con la apuesta civilizatoria por un «gobierno de las leyes» frente a un "gobierno de los hombres». Y por otro lado, la idea opuesta de que el completo sometimiento del juez a la ley implica la completa anulación de toda su capacidad intelectual no deductiva tampoco tiene un adecuado asiento en el derecho del Estado constitucional moderno. Dicho derecho se concibe como un sistema normativo no sólo de reglas, que como tales gozan de una presunción prima facie de aplicabilidad, sino también de principios a la luz de los cuales aquéllas deben ponderarse en cada situación, especialmente en los frecuentes casos dudosos.

\section{BIBLIOGRAFÍA}

Alchourrón, Carlos E., y Bulygin, Eugenio (1991): «Los límites de la lógica y el razonamiento jurídico», en Análisis lógico y Derecho, CEC, Madrid, 303-328.

ALEXY, Robert (1989): Teoria de la argumentación jurídica, CEC, Madrid.

- (1995): Recht, Vernunft, Diskurs, Suhrkamp, Francfort.

AtIEnza, Manuel (1986): Sobre la analogía en el Derecho, Civitas, Madrid.

- (1991): Las razones del Derecho, CEC, Madrid.

Atienza, Manucl, y Rurz Manero, Juan (1996): Las piezas del Derecho. Teoría de los enunciados jurídicos, Ariel, Barcelona.

Bayón, Juan Carlos (1996): «Principios y reglas: legislación y jurisdicción en el Estado constitucional», en Jueces para la democracia, núm. 27 (1996), 41-49.

BeCCARIA, Cesare (1988): De los delitos y las penas, Alianza, Madrid.

BobBro, Norberto (1965): Derecho y lógica, Universidad Nacional Autónoma de México, México.

- (1991): Teoría general del Derecho, Debate, Madrid.

DwORkin, Ronald (1984): Los derechos en serio, Ariel, Barcelona.

- (1988): El imperio de la justicia, Gedisa, Barcelona.

FerRajoli, Luigi (1995): Derecho y razón, Trotta, Madrid.

Garcia Amado, Juan Antonio (1988): Teorias de la tópica jurídica, Civitas, Madrid.

GASCÓN ABELLÁN, Marina (1993): La técnica del precedente y la argumentación racional, Tecnos, Madrid.

GünTHER, Klaus (1988): Der Sinn für Angemessenheit, Suhrkamp, Francfort.

- (1995): «Un concepto normativo de coherencia para una teoría de la argumentación jurídica», en Doxa, núms. 17-18, 271-302.

HABERMAS, Jürgen (1982): Conocimiento e interés, Taurus, Madrid.

- (1987): La teoria de la acción comunicativa, Taurus, Madrid.

- (1988): «Entgegnung», en A. HONNETH y H. JOAS (eds.), Kommunikatives Handeln, Suhrkamp, Francfort, 327-405.

- (1989): Teoria de la acción comunicativa: complementos y estudios previos, Cátedra, Madrid.

- (1991); Erläuterungen zur Diskursethik, Suhrkamp, Francfort.

- (1998): Facticidad y validez, Trotta, Madrid.

HaRT, H. L. A. (1963): El concepto de Derecho, Abeledo-Perrot, Buenos Aires. KaLtNowski, Georges (1973): Introducción a la lógica jurídica, EUDEBA, Bucnos Aires. Kı.us, Ulrich (1961): Lógica juridica, Sucre, Caracas. 
- (1989): «Problemas de la lógica de la argumentación jurídica en el proceso judicial», en ídem, Problemas de la filosofía y de la pragmática del Derecho, Alfa, Barcelona, $75-86$.

MACCorMick, Neil (1978); Legal Reasoning and Legal Theon, Clarendon Press, Oxford. MonTESquieu (1993): Del espiritu de las leyes, Tecnos, Madrid.

MuguerzA, Javier (1994): "El tribunal de la conciencia y la conciencia del tribunal», en Doxa, núms. 15-16, vol. II, 535-560.

Peczenik, Alexander (1992): «Los principios jurídicos según Manuel Atienza y Juan Ruiz Manero", en Doxa, núm. 12, 327-331.

Perelman, Chaïm, y Olbrechts-Tyteca, L. (1989): Tratado de la angumentación. La nueva retórica, Gredos, Madrid.

Prieto Sanchis, Luis (1992): Sobre principioss y nomas. Problemas del razonamiento jurídico, CEC, Madrid.

Thiebaut, Carlos (1992): Los limiles de la comunidad, CEC, Madrid.

Tuori, Kaarlo (1988); «Ética discursiva y legitimidad del Derecho», en Doxa, núm. 5, 47-67.

Utrera Garcia, Juan Carlos (1995): «Apuntes sobre la teoría de los derechos fundamentales de $R$. Alexy», en Derechos y libertades, núm. 4, 355-379.

Velasco, Juan Carlos (1997): «Entre universalismo y contextualismo: la aplicación de las normas morales y jurídicas», en Isegoría, núm. 17, 204-207.

VIEHwEG, Theodor (1986): Tópica y jurisprudencia, Taurus, Madrid.

- (1991): Tópica y filosofía del Derecho, Gedisa, Barcelona.

Walzer, Michael (1996): Moralidad en el ámbito local e intemacional, Alianza, Madrid.

WELLMER, Albrecht (1988): «Razón, utopía y dialéctica de la ilustración», en Habermas y la modernidad (colectivo), Cátedra, Madrid.

Wittcenstein, Ludwig (1988): Investigaciones filosóficas, Crítica, Barcelona. 